\title{
Justice in Nanotechnological Development (Symposium Introduction)
}

\author{
Ulrik B. Nissen
}

Received: 28 July 2009 /Accepted: 28 July 2009 /Published online: 11 August 2009

(C) Springer Science + Business Media B.V. 2009

In October 2008 the Nano Ethics Network held its third workshop at Aarhus University, DK. The theme of the workshop was justice in nanotechnological development. A few of the presentations held at this workshop are brought here as a 'symposion'.

The issue of justice has developed during the last couple of years to be one of the central ethical issues related to nanotechnological developments. A whole variety of issues such as e.g. the relation between knowledge power and distribution of research funding, the north-south divide in terms of economy, intensity of knowledge bases and political power, the associated potential risks and who will suffer these risks are implied in this discussion. The debate on justice in relation to nanotechnological developments raises many questions that need to be addressed.

During the workshop only a few of these issues could be discussed. In the following three papers, some of these questions and concerns are raised. In the paper by Foladori et al the focus is on the socioeconomic structures and forces in both developed and developing countries. The question is raised, if the development of nanotechnology and nanotechnologically related products either reinforces or reduces the socio-economic injustices prevalent in many of the

\section{U. B. Nissen $(\triangle)$}

Department of Systematic Theology, Aarhus University, Bygning 1443, Tåsingegade 3, DK - 8000 Århus C, Denmark e-mail: UBN@teo.au.dk developing countries. The paper argues that the fundamental challenge lies at the root of the socioeconomic systems that tend to increase inequalities.

Jamison takes a fresh look at the development of nanotechnology and its relation to the emerging movement for global justice. Jamison argues that much of the nanotechnological development is characterized by a hubris which disregards the societal implications and justice related issues implicit in this field. As the forums where the critical reflection on emerging technologies have changed during the last couple of decades, much of the critical potential has become silent. It is within an emerging group of organizations related to issues of global justice that we find the critical voice which could be integrated in the discussion on justice issues related to the development of nanotechnology.

Maclurcan reports on research concerning the socalled 'nano-divide'. In a comparison of the results from interviews in various professional sectors related to nanotechnological R\&D in Thailand and Australia, it is argued that a list of issues is involved in determining, if there is a nano-divide and what this entails. Maclurcan reaches the conclusion that various factors further the nano-divide and some aspects may be seen as a potential for developing countries.

Even if it is only a provisional step, the three papers brought here contribute with significant insight in this much needed debate. It remains as a hope that these papers will stimulate the debate even further, as nanotechnological research continues to develop in new directions no less in need of this discussion. 